\title{
TRASCENDENCIA SOCIO-ECONÓMICA DEL TRASVASE TAJO SEGURA TRAS 30 AÑOS DE SU FUNCIONAMIENTO EN LA PROVINCIA DE ALICANTE
}

\author{
María Hernández Hernández \\ Alfredo Morales Gil \\ Departamento de Análisis Geográfico Regional y Geografía Física \\ Universidad de Alicante
}

\section{RESUMEN}

La espectacular transformación del regadío, ocurrida desde mediados de la década de los setenta en el sur de la provincia de Alicante, ha producido una mudanza radical, que ha afectado no sólo a la distribución de cultivos, sino también a las estructuras de la propiedad de la tierra y a las características de las explotaciones. El objetivo de este artículo es poner de manifiesto las repercusiones sociales y económicas derivadas de la ampliación de los recursos hídricos disponibles en el sur de la provincia de Alicante.

Palabras clave: cultivos hortofrutícolas, Alicante, trasvase Tajo-Segura, repercusiones sociales y económicas, mano de obra.

\section{ABSTRACT}

Socio-economic significance of Tagus-Segura transfer after 30 years of bringing into service in the province of Alicante (Spain)

The remarkable change of irrigation areas, happened from middle of the seventies in the south of Alicante province, has produced a radical transformation, which has affected not only to the distribution of crops, but also to land property structures and exploitation attributes. The aim of this article is to reveal social and economic repercussions derived from water available resources enlargement.

Key words: fruit and vegetables crops, Alicante, Tagus-Segura transfer, social and economic repercussions, workforce.

\section{Introducción}

La penuria natural de recursos hídricos, que padece el territorio del sur de la provincia de Alicante, ha propiciado que el agua adquiriese ya desde época romana el carácter 
de bien por excelencia. Se ha creado, así, una cultura histórica con sistemas originales y reglamentaciones muy minuciosas para su captación, distribución y aprovechamiento en torno al río Segura, eje vertebrador del territorio (Morales, Rico y Hernández, 2005). Las condiciones climáticas características de estas tierras definidas, grosso modo, por unas 2.900 horas de sol al año, unas precipitaciones escasas, inferiores a los $300 \mathrm{~mm}$, y una fuerte evapotranspiración, alrededor de $900 \mathrm{~mm}$./año (Olcina, 2003), determinaban el predominio de los secanos, salvo en la reducida superficie beneficiada con los caudales de los cursos fluviales.

El carácter estratégico del agua y de los espacios regados explica que las actuaciones orientadas a la ampliación de los recursos hídricos disponibles hayan sido una constante a lo largo del tiempo. Estos procesos, que se han traducido en notables repercusiones desde el punto de vista de las superficies regadas y de la difusión de nuevos aprovechamientos, van a permitir el paso, de una agricultura de secano extensiva y dependiente de la aleatoriedad de las cosechas, a una intensiva y con una clara orientación a los mercados internacionales. La espectacular transformación del regadío, ocurrida desde mediados de la década de los setenta, ha producido una mudanza radical, que ha afectado no sólo a la distribución de cultivos sino también a las estructuras de la propiedad de la tierra, los regímenes de tenencia y las características de las explotaciones. Notables son, igualmente, las repercusiones desde el punto de vista económico y social. La agricultura que se difunde por estas tierras (horticultura de ciclo manipulado y la citricultura) se aparta de los modelos generales de desarrollo agrario, al no provocar el éxodo rural que la modernización de la agricultura extensiva originó en los años sesenta en todo el campo español, si no, por el contrario, allí donde se ubica aparece un foco de inmigración que atrae a la población de las comarcas interiores y de regiones vecinas menos desarrolladas, dada la demanda de mano de obra, tanto directa como indirecta, que precisa este tipo de cultivos. Su orientación hacia la exportación se refleja, entre otros indicadores, en la aportación al producto bruto regional. Según datos de 2006, por ejemplo, las exportaciones españolas de frutas y hortalizas a los mercados europeos alcanzaron un valor de 7.388 millones de euros, de las que aproximadamente el 34\% corresponde a la Comunidad Valenciana, gracias a los envíos de cítricos y hortalizas, que representan algo más de un 56\% de las exportaciones agroalimentarias de esta comunidad (Generalitat Valenciana, 2007).

El objetivo de este artículo es poner de manifiesto las repercusiones socioeconómicas derivadas de la ampliación de los recursos hídricos disponibles en la provincia de Alicante (comarcas del Bajo Vinalopó y Bajo Segura) y, más concretamente, de la llegada de caudales procedentes del Tajo. Para ello, se examinará la evolución de las superficies regadas desde finales de los años setenta, con especial atención a las transformaciones registradas en los cultivos dominantes en la última década. Ello nos permitirá, teniendo en cuenta la demanda de mano de obra por unidad de superficie según cultivo, una aproximación a las repercusiones socioeconómicas de estos cultivos (mano de obra empleada, aportación de esta agricultura al producto interior bruto, renta familiar disponible, etc.).

\section{Evolución de las superficies regadas y de los aprovechamientos}

La combinación de una serie de factores edáficos, climáticos, hidrográficos e hidrogeológicos, unida a un exhaustivo aprovechamiento de la oferta natural de agua disponible, explica, el extraordinario desarrollo que ha alcanzado el regadío en las vegas del Segura (alicantinas y murcianas). Hitos en su configuración son la concesión a la Sociedad de Riegos de Levante en 1923 de los sobrantes existentes en la desembocadura del río Segura, que beneficiaron a unas 4.000 ha, y la promulgación del Decreto de 25 de abril de 1953 de 
Ampliación de los regadíos de la cuenca del Segura1. La consolidación de regadíos tradicionales y, sobre todo, la expansión de nuevas áreas regadas mediante las transformaciones en regadío de secanos, eriales o monte bajo se ha producido, sobre todo, durante la segunda mitad del siglo XX debido a la utilización de potentes bombas que extraen las aguas de los acuíferos subterráneos, de las actuaciones hidráulicas como el trasvase Tajo-Segura y las obras de colonización auspiciadas por la administración (INC e IRYDA). El Decreto de 15 de marzo de 1973 por el que se regulaba las actuaciones de reforma y desarrollo agrario en las áreas receptoras del trasvase Tajo-Segura definió seis zonas regables en la denominada Comarca Meridional de Alicante. Dos de estas zonas regables, los regadíos tradicionales de la Vega Baja del Segura, unas 18.000 hectáreas, y la zona regable de El Porvenir, quedaron sin dotaciones del Trasvase al disponer de los caudales del Segura, cuyos recursos se repartieron entre las otras cuatro (Riegos de Levante margen izquierda, Riegos de Levante margen derecha, La Pedrera y Saladares de Albatera), en función de las necesidades entonces estimadas. Atendiendo a las tierras adscritas a las entidades que distribuyen el agua procedente del Alto Tajo en la provincia de Alicante, las superficies afectadas ascenderían a unas 30.000 hectáreas (Tabla 1). A éstas, deben incorporarse 3.844 regadas en el término municipal de Pilar de La Horadada a través del Canal de Campo de Cartagena. Esta cifra engloba realidades diversas, ya que incluía tanto a superficies, concretamente las de Riegos de Levante en ambas márgenes, que fueron redotadas como las de nuevos regadíos sensu stricto, unas 12.000 hectáreas (Fig. 1).

Tabla 1

SUPERFICIE REGABLE CON AGUAS DEL TRASVASE SEGÚN ENTIDADES DISTRIBUIDORAS (2008)

\begin{tabular}{|l|r|}
\hline \multicolumn{1}{|c|}{ Entidad } & Superficie (ha) \\
\hline Riegos de Levante. Margen izquierda & 20.164 \\
Riegos de Levante. Margen derecha & 1.035 \\
La Pedrera & 7.044 \\
Saladares de Albatera & 1.385 \\
Canal Campo de Cartagena (Pilar Horadada) & 3.844 \\
\hline Total & $\mathbf{3 3 . 4 7 2}$ \\
\hline
\end{tabular}

Fuente: Sindicato Central de Regantes del Acueducto Tajo-Segura. Elaboración propia

En el área de estudio, los aportes del trasvase Tajo-Segura (Tabla 2) resultan trascendentales para el mantenimiento de las superficies regadas. La obra fue diseñada con el objetivo final de trasvasar $1.000 \mathrm{hm}^{3}$ en dos fases, una primera de $600 \mathrm{hm}^{3} / \mathrm{año}$, y una segunda de $400 \mathrm{hm}^{3} /$ año adicionales (Morales, Rico y Hernández, 2005). Las expectativas generadas por el trasvase Tajo-Segura fueron tales que, en palabras de los técnicos y las autoridades hidráulicas, esta obra triplicaría la zona regable, resolvería definitivamente el problema del

1 La mayor regulación de la cuenca, a partir de la construcción de una serie de embalses en la cabecera del Segura (Cenajo y Camarillas), debía garantizar los recursos de agua necesarios para el riego de unas 21.500 ha. de regadíos tradicionales de la Vega Baja del Segura y de otras 3.500 de tierras aledañas (Morales, 1996). 


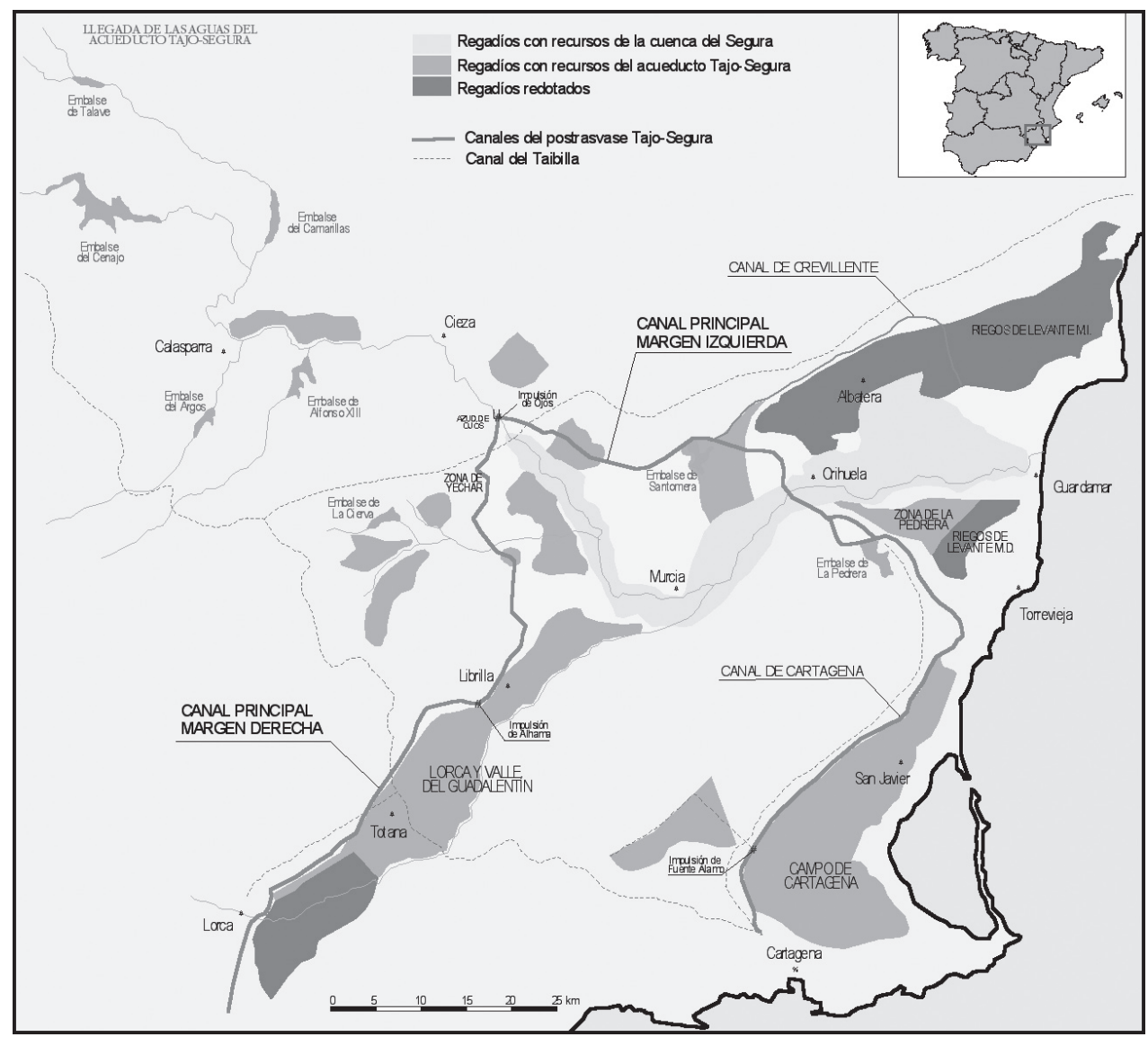

Figura 1. Regadíos tradicionales, nuevos regadíos y redotados beneficiados por los caudales del trasvase Tajo-Segura en la cuenca de este último.

Fuente: Morales, Rico y Hernández, 2005.

abastecimiento e impulsaría el desarrollo industrial y turístico de las zonas receptoras. La realidad, sin embargo, ha sido menos ambiciosa que la que contemplaban sus promotores, ya que si bien estos recursos han paliado en algo el déficit hídrico, no ha solucionado los problemas de escasez de recursos. Sin embargo, está fuera de toda duda que la llegada del trasvase del Tajo a la cuenca del Segura ha contribuido a aliviar la situación de sequía crónica que padecía esta zona, generando un proceso de desarrollo económico positivo en estas tierras, además de aportar caudales de calidad a estas tierras. El promedio de agua trasvasada desde 1979 a 2008, asciende a $328 \mathrm{hm}^{3} /$ año, lo que supone alrededor del $53 \%$ del volumen previsto inicialmente. La contracción de trasvase ha afectado primordialmente al regadío, cuya dotación puede considerarse reducida, por término medio, en esta primera fase, a una tercera parte de la esperada. Esta disminución se ve incrementada por el aumento de la demanda para usos urbanos, que ha superado en un $10 \%$ la prevista inicialmente; mengua que se acentúa en los periodos de sequía. El análisis sucinto de la tabla 2 pone de manifiesto, igualmente, que éstos se completan con otros caudales, concretamente los sobrantes del Segura (extraídos en desembocadura por riegos de Levante), las captaciones 
Tabla 2

RECURSOS HÍDRICOS, ATENDIENDO A SU PROCEDENCIA, UTILIZADOS EN EL ÁREA DE ESTUDIO

\begin{tabular}{|c|c|c|c|c|}
\hline \multirow[b]{2}{*}{$\begin{array}{c}\text { Año } \\
\text { hidrológico }\end{array}$} & \multicolumn{3}{|c|}{ Trasferencias Tajo- Segura $\left(\mathrm{hm}^{3}\right)$} & \multirow{2}{*}{$\begin{array}{c}\text { Recursos hídricos de } \\
\text { otras procedencias } \\
\text { utilizados en el área de } \\
\text { estudio }\left(\mathbf{h m}^{3}\right)\end{array}$} \\
\hline & Total & $\begin{array}{c}\text { Para } \\
\text { Regadío }\end{array}$ & $\begin{array}{l}\text { Para regadío } \\
\text { (área de } \\
\text { estudio) }\end{array}$ & \\
\hline $1978-1979$ & 63,15 & 41,14 & 14,30 & 186,54 \\
\hline $1979-1980$ & 36,00 & 25,75 & 8,95 & 191,88 \\
\hline 1980-1981 & 253,06 & 164,62 & 57,21 & 143,63 \\
\hline 1981-1982 & 344,61 & 207,18 & 72,00 & 128,84 \\
\hline 1982-1983 & 94,10 & 37,24 & 12,94 & 187,89 \\
\hline 1983-1984 & 141,11 & 71,03 & 24,68 & 176,15 \\
\hline 1984-1985 & 349,75 & 231,85 & 80,57 & 120,26 \\
\hline $1985-1986$ & 353,02 & 233,79 & 81,24 & 119,59 \\
\hline 1986-1987 & 377,20 & 234,17 & 81,37 & 119,46 \\
\hline $1987-1988$ & 375,46 & 234,40 & 81,45 & 119,38 \\
\hline 1988-1989 & 359,45 & 208,75 & 72,54 & 128,29 \\
\hline 1989-1990 & 263,31 & 125,62 & 43,65 & 157,18 \\
\hline 1990-1991 & 315,80 & 178,00 & 61,86 & 138,98 \\
\hline 1991-1992 & 264,80 & 108,00 & 37,53 & 163,30 \\
\hline 1992-1993 & 191,50 & 50,00 & 17,38 & 183,46 \\
\hline 1993-1994 & 250,00 & 115,00 & 39,96 & 160,87 \\
\hline 1994-1995 & 206,57 & 55,00 & 19,11 & 181,72 \\
\hline 1995-1996 & 342,77 & 213,00 & 74,02 & 126,81 \\
\hline 1996-1997 & 490,00 & 320,00 & 111,20 & 89,63 \\
\hline 1997-1998 & 447,00 & 317,00 & 110,16 & 90,67 \\
\hline 1998-1999 & 546,00 & 392,00 & 136,22 & 64,61 \\
\hline $1999-2000$ & 597,00 & 416,00 & 144,56 & 56,27 \\
\hline $2000-2001$ & 620,00 & 444,50 & 154,46 & 46,37 \\
\hline $2001-2002$ & 536,50 & 361,00 & 125,45 & 75,38 \\
\hline $2002-2003$ & 514,00 & 333,50 & 115,89 & 84,94 \\
\hline 2003-2004 & 532,00 & 361,50 & 125,62 & 75,21 \\
\hline 2004-2005 & 422,50 & 268,00 & 93,13 & 107,70 \\
\hline $2005-2006$ & 186,50 & 38,00 & 13,21 & 187,63 \\
\hline $2006-2007$ & 188,00 & 31,00 & 10,77 & 190,06 \\
\hline $2007-2008$ & 178,66 & 60,40 & 20,99 & 179,84 \\
\hline
\end{tabular}

Las dotaciones para regadío vienen reguladas por las Ordenanzas del Sindicato Central de Regantes del Acueducto Tajo-Segura, que sancionan la dotación asignada a cada comunidad de regantes, atendiendo a la superficie de cada una de ellas. En estas ordenanzas, se recoge igualmente, que en situación de escasez de recursos se procederá a su reparto con arreglo a las disposiciones legales y respetando las proporciones de volúmenes establecidos en las mismas (art. 7), es decir, se distribuye el caudal trasferido proporcionalmente a la concesión estipulada.

El item «recursos hídricos de otras procedencias utilizados en el área de estudio» es el resultado de a los caudales del Tajo restar la demanda generada por las superficies que, según las ordenanzas que regulan esta transferencia, pueden beneficiarse con esos caudales y una dotación media asignada por superficie $\left(6.000 \mathrm{~m}^{3} / \mathrm{ha}\right)$.

Fuente: Sindicato Central de la Comunidad General de Regantes del Acueducto Tajo-Segura. Elaboración propia. 
subterráneas que han generado una notable sobreexplotación de los acuíferos y la reutilización de aguas depuradas y recientemente, desaladas; recursos que incrementan su importancia, coincidiendo con aquellos períodos (sequías) en los que las transferencias desde el Tajo se reducen notablemente. Es, en gran medida, la utilización de recursos mixtos, o, incluso, mayoritariamente subterráneos, completados con recursos no convencionales, los que han permitido en gran medida la expansión de estas superficies regadas.

La combinación de estos recursos ha permitido ampliar las 18.000 hectáreas regadas a mediados del siglo XX, que constituían el regadío tradicional, a unas 26.000 a principios de los años setenta y a las 59.940 de 2006 en el área objeto de estudio. Estas superficies han registrado una disminución de unas 14.000 hectáreas con respecto a las irrigadas en 1998. Las causas que explican el cambio de dinámica, que se sitúa a finales de los años noventa, se relacionan con la expansión de los usos turístico-residenciales y la competencia que éstos ejercen sobre el recurso suelo y agua, sin olvidar la mano de obra. Ello determina la necesidad de una rentabilidad alta de las actividades agrarias, ya que en caso contrario, sucumben a la expansión residencial o se convierten en barbecho social en espera de obtener cuantiosas plusvalías mediante su conversión en suelos urbanizables. A este factor, se une el abandono de aquellas explotaciones, especialmente, las que se asientan en las proximidades de la vega histórica del río Segura y, en general, de todas aquellas que no se adecuan a las demandas del mercado. Genéricamente, se puede sintetizar esta problemática en la inadecuada dimensión de las explotaciones, el predominio de especies varietales de bajo valor en el mercado, incidencia negativa para algunos cultivos arbóreos de la superficialidad del nivel freático, además del elevado riesgo de inundación y mayor riesgo de helada por inversión térmica.

A principios de los años 70, en la comarca de la Vega Baja en los regadíos predominaban los cereales y las hortalizas (alcachofa, pimiento para pimentón, habas verdes y guisantes) que ocupaban, el 30 y el 50\%, respectivamente de los herbáceos y los cítricos que se extendían sobre el 60\% del terrazgo de los leñosos (Vera, 1984). En el Bajo Vinalopó, eran los leñosos, concretamente almendros y algarrobos, los cultivos dominantes (Gozálvez, 1973); lo que constituía una excepción en el agro provincial, en el que los herbáceos eran los aprovechamientos mayoritarios en las tierras regadas. El incremento de las superficies regadas ha ido asociado a la sustitución de cultivos con una clara orientación hacia el mercado, que se plasma en una progresiva especialización en aquellos de mayor rentabilidad (cítricos y hortalizas), y, paralelamente, el abandono de los menos productivos (cereales). Los cítricos, que concentran el $77 \%$ de la superficie ocupada por los leñosos en 2006, ven incrementado este valor en 10 puntos porcentuales con respecto a 1998. Las hortalizas, con el $58 \%$ de la superficie de los herbáceos en regadío, aumentan su especialización en 20 puntos en relación a 1998. La tendencia descrita conduce a la introducción y posterior consolidación de aprovechamientos de mayor rentabilidad como pueden ser las flores y las plantas ornamentales. Las 107 hectáreas de 1998 ascienden a unas 738 en 2006; afianzándose como la principal área productora al reunir alrededor del $95 \%$ de la superficie provincial, que a su vez se concentra en los municipios de Elche y Pilar de la Horadada, donde se localizan la práctica totalidad de los invernaderos con tecnología de alta vanguardia, y un 43\% de la superficie nacional en 2005 (MAPA, 2007: 60).

Los cítricos, con sus 27.079 ha., son el aprovechamiento mayoritario en regadío en el área de estudio ${ }^{2}$. En el último decenio, han registrado un ligero incremento (643 ha) que

2 Desempeñan, asimismo, un papel trascendental a escala provincial: el 67,7\% de las superficies de naranjo se localizan en el área de estudio, porcentaje que asciende al 90,3\% en el caso del limón y al 41,4\% en la mandarina. 
Tabla 3

EVOLUCIÓN DE LAS SUPERFICIES OCUPADAS POR LOS PRINCIPALES APROVECHAMIENTOS (1998-2006)

\begin{tabular}{|l|r|r|r|r|r|r|}
\hline \multirow{2}{*}{} & \multicolumn{2}{|c|}{1998} & \multicolumn{2}{c|}{2006} & \multicolumn{2}{c|}{$\begin{array}{c}\text { Evolución } \\
2006-1998\end{array}$} \\
\cline { 2 - 7 } & ha & $\%$ & ha & $\%$ & ha & $\%$ \\
\hline Cítricos & $\mathbf{2 5 . 3 2 5}$ & $\mathbf{6 6 , 0}$ & $\mathbf{2 6 . 3 2 8}$ & $\mathbf{7 7 , 2}$ & $+\mathbf{6 4 3}$ & $+\mathbf{1 1 , 5}$ \\
- naranjo & 11.808 & 46,6 & 12.553 & 47,6 & +745 & $+4,0$ \\
- mandarino & 1.346 & 5,3 & 3.403 & 12,9 & +2057 & $+7,6$ \\
- limonero & 13.098 & 51,7 & 10.702 & 40,6 & -2.396 & $-11,1$ \\
\hline hortalizas & $\mathbf{7 . 4 0 1}$ & $\mathbf{3 7 , 0}$ & $\mathbf{8 . 2 4 1}$ & $\mathbf{5 8 , 3}$ & $+\mathbf{8 4 0}$ & $+\mathbf{2 1 , 3}$ \\
- lechuga & 809 & 10,9 & 950 & 11,5 & +141 & $+0,1$ \\
- melón /sandía & 531 & 7,1 & 1.006 & 12,2 & +475 & $+5,1$ \\
- tomate & 455 & 7,1 & 84 & 1,0 & -371 & $-6,1$ \\
- pimiento & 410 & 5,5 & 184 & 2,2 & -226 & $-3,3$ \\
- alcachofa & 1.870 & 25,2 & 1.709 & 20,7 & -161 & $-4,7$ \\
- bróculi & 1.021 & 13,8 & 2.464 & 29,9 & +1.443 & $+16,1$ \\
- flores & 147 & 0,75 & 738 & 5,21 & +591 & $+4,4$ \\
\hline
\end{tabular}

La trascendencia de los cultivos hortícolas y de las flores se acentúa si tenemos en cuenta que en algunos de ellos se practican varios ciclos de cultivo en una misma parcela en un año: en las lechugas como mínimo se llevan a cabo hasta 3 ciclos de cultivo por parcela y año, 2 ciclos en las rosas y de 4 a 5 en claveles. Fuente: Hojas 1-T. Elaboración propia.

encubre una trayectoria negativa que se plasma en el no cultivo de importantes superficies en los dos últimos años (2007-2008), que no recoge esta tabla, al no estar disponible esta fuente estadística (Hojas 1-T), pero incuestionable al realizar trabajo de campo y encuestas a los agricultores. Desde la década de los noventa, los cítricos han experimentado un importante proceso de ajuste productivo (Tabla 3 ) dirigido a sustituir variedades de naranjos por otras de mandarinos, dada la menor rentabilidad económica de aquellos, al registrar cada vez más una mayor competencia de producciones en fresco y en zumo procedentes de Marruecos, Israel, Sudáfrica o Brasil. Los cambios varietales acaecidos en los mandarinos (frutos más precoces, sin semillas, de fácil pelado, con mejores condiciones organolépticas y con posibilidad de propiciar ritmos de recolección escalonados durante la campaña de comercialización) han permitido su adaptación a los gustos de los consumidores, por lo que algunas de sus variedades (clementinas de las variedades oroval, clemenules o marisol) son muy competitivas en los mercados de la Unión Europea, Canadá o Estados Unidos. A pesar de estas transformaciones, un porcentaje importante de estos cítricos presenta importantes problemas de rentabilidad, que se han plasmado en el significativo abandono de superficies en los últimos años. La evolución de las superficies ocupadas por el limón es un ejemplo paradigmático. De constituir un aprovechamiento mayoritario en la Vega Baja, la caída drástica en los precios percibidos a pie de parcela ${ }^{3}$ se ha plasmado en una reducción de la superficie ocupada y, paralelamente, su sustitución

3 La variabilidad en los precios queda corroborada comparando los precios percibios a pie de parcela en la campaña 2007/08, 0,96€/kg, concretamente en mayo de 2008 , frente a los $0,15 €$, por debajo de los costes de producción de mayo de 2007 (campaña 2006/2007) (Conselleria de Agricultura, 2008). 
por otras variedades de cítricos (naranjas tardías y mandarinas): la superficie ocupada sobre el total de la de cítricos ha pasado de ocupar alrededor del 50 al 40\% entre 1998 y 2006. La variabilidad de los precios se relaciona con factores diversos entre los que debe citarse la competencia ejercida por terceros países, que varía dependiendo de las condiciones climáticas invernales en algunos de ellos y la aplicación de aranceles a la importación. Las aproximadamente 2.400 hectáreas de limonero que han desparecido han sido compensadas por las casi 3.000 nuevas de naranjos y mandarinos.

Los cultivos hortícolas ven ampliadas las 7.401 hectáreas de 1998 en unas 840 ha. Su dinámica es, sin embargo, inversa a la de los cítricos: la tendencia es hacia el aumento continuo de los terrazgos ocupados por este aprovechamiento. Siendo el área de estudio, con sus 8.241 ha., la principal comarca por superficie de la provincia de Alicante dedicada a la horticultura de ciclo manipulado al aire libre y protegido ${ }^{4}$; superficie que equivale al sexto lugar en el conjunto nacional. Desde la década de los noventa, han registrado una intensa especialización en cultivos tempranos y extratempranos frente a otros más tradicionales o con demanda estancada o regresiva en el mercado (haba, judía verde o berenjena, entre otros). Concretamente, en producciones como la alcachofa, la lechuga, el bróculi o el melón, el área de estudio reúne más del $85 \%$ del total provincial. Esta especialización se ha mantenido e, incluso, se ha acelerado en los últimos dos años, sobre todo, en los piedemontes de las sierra de Abanilla y Crevillente. La evolución que han registrado aprovechamientos como el bróculi, el melón, el tomate, el pimiento, la lechuga o la alcachofa resultan paradigmáticas (tabla 3). El bróculi y el melón presentan incrementos muy importantes. Ambos han visto duplicadas las superficies; convirtiéndose el primero de ellos en el cultivo que ocupa la mayor extensión dentro del epígrafe hortalizas. Una tendencia inversa caracteriza a tomates y pimientos, que ven reducida significativamente su superficie: el primero como consecuencia de la caída de los precios por la competencia del producto marroquí y el segundo por el encarecimiento de costes al desarrollarse en invernadero de alta tecnología, lo que se ha traducido en una reducción notable de la extensión ocupada en el principal municipio productor (Pilar de la Horadada) y su reconversión hacia otros aprovechamientos de mayor rentabilidad (flores). En una situación intermedia (mantenimiento o ligero incremento o reducción) se encuentran cultivos como la lechuga y la alcachofa. Éste último, que era el principal cultivo por superficie, ha cedido su primacía al bróculi, dados los mayores precios percibidos a pié de parcela de éste último.

\section{La rentabilidad socio-económica de los cultivos}

\section{Una agricultura, que demanda mano de obra}

El predominio de cultivos hortícolas y frutícolas de clara orientación al mercado, que demandan una elevada mano de obra tanto directa como indirecta, unido al dinamismo que caracteriza a estas comarcas litorales determina importantes repercusiones sociales, vinculadas a la creación y posterior consolidación de este tipo de agricultura. Lejos del tópico de que toda crisis en la agricultura implica la reducción de las superficies agrícolas y la pérdida de empleos, una contracción de ésta no significa, siempre, disminución de activos y merma de ingresos. Dependiendo de una serie de variables, puede denotar la conversión hacia cultivos más especializados, que requieran mayor mano de obra, generen más ingresos, etc. Este es el caso del área objeto de estudio: el abandono de tierras 
regadas, tanto en leñosos como en herbáceos, ha afectado a los aprovechamientos más extensivos (cereales o frutales); en cambio, se han incrementado las ocupadas por hortalizas, flores y plantas ornamentales cuyo cultivo precisa más mano de obra por hectárea cultivada. Así, una de cereales oscila entre las 0,05 y 0,17 UTA/ha o lo que es lo mismo, es necesario cultivar entre 20 y 6 hectáreas para generar una unidad de trabajo ${ }^{5}$. En el caso de los cítricos, con 0,45 UTA/ha/año, se requiere algo más de 2 hectáreas para dar empleo a un trabajador, mientras que una de lechugas genera entre 3 y 4 unidades de trabajo por hectárea (Morales, 1997: 93-128). Igualmente, ahora que se está produciendo un retraimiento de la superficie regada, sobre todo, en cítricos y un pequeño avance de los hortícolas, al aire libre y en invernadero, la mano de obra para la agricultura se mantiene en la misma cuantía que con anterioridad a la escasez de recursos hídricos de 2007-2008 e incluso se observa la incorporación de parte del excedente que está generando la crisis en la construcción (fig.2). Cuestión esta de notable trascendencia, dada la fuerte competencia que existe por los recursos suelo, agua y mano de obra con las actividades turístico-residenciales.

La evolución diacrónica de los activos (Hernández y Torres, 2003) pone de manifiesto las transformaciones acaecidas en la estructura económica de estas comarcas a partir de la década de los setenta. Las nuevas dinámicas se traducen en una progresiva terciarización de la población activa al amparo de la importancia creciente de las actividades turísticoresidenciales, del sector de la construcción y el incremento de los activos secundarios gracias a los procesos de difusión industrial y, paralelamente, el decrecimiento constante de los activos agrarios. La reducción de éstos últimos es un proceso que ha acontecido, pero debe ser matizado, ya que es mucho menor que en comarcas próximas, donde éstos son prácticamente testimoniales. Además, se genera en un contexto de fuerte dinamismo económico, lo que permite deducir que los activos que permanecen lo hacen porque esta actividad les genera ingresos similares a otras actividades y no por falta de expectativas laborales. La consulta del número de empresarios y trabajadores según su cotización a la

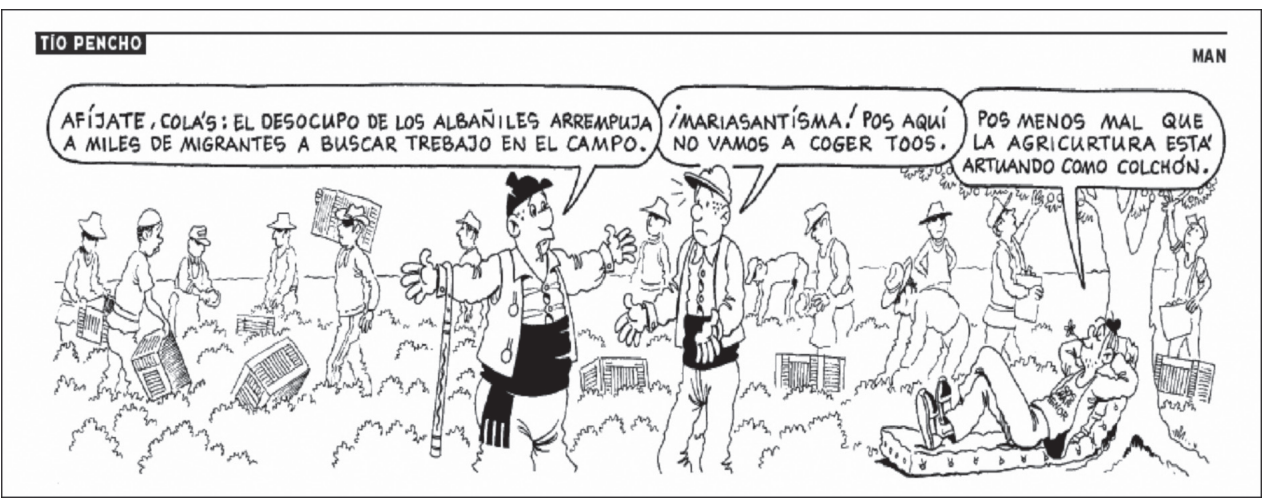

Figura 2. Cuando se esta agudizando la crisis económica, que en Alicante, afecta directamente a la construcción, se aprecia un trasvase de mano de obra de este sector a la hortofruticultura. Así, hasta la prensa diaria en clave de humor lo recogía. Fuente: Periódico La Verdad, edición del 17-6-2008. Autorizada su reproducción por e-mail. Fecha 7-7-2008.

5 La unidad de trabajo agrario (UTA) se define como el trabajo efectuado por una persona dedicada a tiempo completo durante un año a la actividad agraria, equivalente a 1.950 horas ó 240 jornales. 
Seguridad Social a fecha de junio de 2007 refleja que el sector agrícola continúa teniendo una importancia notable en estas comarcas: alrededor del 50\% tanto de los empresarios como de los trabajadores inscritos bajo el código 1 (CNAE-93), es decir, el que corresponde a las actividades agrarias, en la provincia de Alicante se concentra en este área de estudio. Igualmente, pone de manifiesto que el porcentaje de activos agrarios en estas comarcas (6,65\% de la población activa) duplica al provincial $(3,62 \%)$ e, incluso, en algunos casos lo quintuplica como sucede en municipios como San Miguel de Salinas, Pilar de la Horadada o Benferri, donde los valores se sitúan en torno al $20 \%$ de la población activa. Se debe de destacar, asimismo, que la capacidad de generar empleo por el sector agrícola no se relaciona únicamente con los empleos directos, sino también con aquellos generados por el efecto multiplicador asociado a esta actividad. Este último afecta desde empresas auxiliares vinculadas a la fabricación de plásticos utilizados en los cubrimientos de los invernaderos o para el sistema de regadío, a las empresas que elaboran sustrato para el suelo, semillas, etc. Sin olvidar sectores importantes como son el del transporte de estas frutas y hortalizas, la industria agroalimentaria o el de su manipulación. Éste último requiere un importante volumen de mano de obra, que, se cifra en torno a un $10 \%$ de los activos comarcales. Paradigmática resulta la cooperativa SURINVER en Pilar de la Horadada. La entidad, que cuenta con más de 500 socios, ha puesto en marcha unas instalaciones sobre una parcela de $103.000 \mathrm{~m}^{2}$, donde se integran oficinas, naves de manipulación hortofrutícola y de flores, cámaras frigoríficas, muelles de carga y descarga y los almacenes de suministro para los asociados. De sus 750 empleados en plantilla, aproximadamente 700 se dedican a las tareas de clasificación y manipulación.

Tabla 4

REQUERIMIENTOS DE MANO DE OBRA DE LOS CULTIVOS EN LAS COMARCAS BENEFICIADAS CON LOS CAUDALES DEL TRASVASE TAJO-SEGURA

\begin{tabular}{|l|c|c|c|c|c|}
\hline & $\begin{array}{c}\text { Horas mano } \\
\text { de obra /ciclo } \\
\text { cultivo /ha }\end{array}$ & $\begin{array}{c}\text { Ciclo } \\
\text { cultivo } \\
\left(n^{\boldsymbol{o}}\right)\end{array}$ & UTA/ha & $\begin{array}{c}\text { Superficie } \\
\mathbf{( 2 0 0 6 )}\end{array}$ & $\begin{array}{c}\text { Empleo } \\
\text { directo }\end{array}$ \\
\hline Tomate & 3.500 & 1 & 1,8 & 84 & 151 \\
\hline Lechuga & 1.660 & 4 & 4,3 & 950 & 4.085 \\
\hline Melón & 1.600 & 1 & 1,5 & 1.006 & 1.509 \\
\hline Alcachofa & 2.000 & 1 & 1,1 & 1.709 & 1.880 \\
\hline Pimiento & 7.000 & 1 & 3,6 & 184 & 662 \\
\hline Bróculi & 1.000 & 2 & 1,5 & 2.467 & 3.700 \\
\hline Flores & 7.200 & 1 & 3,6 & 738 & 2.656 \\
\hline Cítricos & 480 & 1 & 0,4 & 27.079 & 10.831 \\
\hline
\end{tabular}

Fuente: Morales, 1997. Trabajo de campo y encuestación. Elaboración propia.

La trascendencia de esta agricultura adquiere una dimensión nueva si se confronta las superficies de cultivo y los requerimientos de mano de obra de éstos. Un análisis sucinto de la tabla 4 pone de manifiesto los elevados requerimientos de mano de obra de estos cultivos, especialmente los hortícolas. Para ello, solo hay que fijarse en el hecho de que las 950 hectáreas dedicadas al cultivo de lechugas generan una demanda de mano de obra 
de unos 4.000 empleos directos, casi el 40\% de los que exigen los cítricos con sus 27.000 hectáreas cultivadas. El cruzar las variables «mano de obra» y «superficie cultivada según aprovechamientos» evidencia la relevancia que el sector agrario desempeña desde el punto de vista social en estas comarcas, que se puede sintetizar en la necesidad de mano de obra y consiguientemente, la existencia de un sector que mantiene población y favorece la diversificación económica de unas comarcas, donde las actividades turístico-residenciales y, sobre todo, la construcción han adquirido en algunos municipios casi un carácter de monocultivo. Estas cifras, sin embargo, ponen de manifiesto una total discordancia con las oficiales. La población activa (trabajadores agrícolas) en estas comarcas ascendía en 2007, según número de afiliados a la Seguridad Social, a 14.417 activos. Éstos deben atender las demandas de mano de obra de las 27.079 hectáreas de cítricos y las 7.138 ocupadas por flores y hortalizas, concretamente de lechuga, tomate, pimiento, melón, alcachofa y bróculi según las cifras de la estadística oficial recogida en las Hojas 1-T, es decir, que sin contar las superficies de secano, aunque minoritarias, y las de otros cultivos practicados en regadío, se dispondría de 0,38 trabajadores por hectárea, muy baja si tenemos en cuanta las altas exigencias de algunos cultivos (Tabla 4). Se confirma la existencia en estas provincias de un empleo agrícola de algo más del doble del admitido oficialmente, que se debe de estar cubriendo por inmigrantes ilegales y, recientemente, por los desplazados de la construcción.

El análisis demográfico de las comarcas beneficiadas por los caudales procedentes de la cabecera del Tajo refleja, igualmente, que nos encontramos ante territorios, donde se ha roto con el ciclo migratorio que, en algunos de ellos, se arrastraba desde finales del siglo XIX, y se ha pasado a otro de inmigración y de un crecimiento vegetativo positivo, superior al que tienen regiones de mayor dinamismo poblacional. En esta dinámica demográfica positiva interviene, no solo, la atracción de población que ejerce la agricultura que se difunde desde mediados de los setenta, sino, también, el sector turístico con una clara impronta, en una primera fase, en municipios litorales como Santa Pola o Torrevieja y, posteriormente, hacia los de segunda línea de costa como Rojales o San Miguel de Salinas, entre otros. Paradigmático resulta Pilar de la Horadada, donde la población ha pasado de unos 7.000 habitantes en 1991 a más de 20.000 según el padrón a 1 de enero de 2007 (INE, 2001 y 2008).

\section{La rentabilidad económica de los cultivos y su incidencia en la renta familiar}

La agricultura de regadío sigue siendo el sustento estructural y fundamental del sector agrícola. Según datos del Plan Nacional de Regadíos, en España, sólo el 14,5\% de la superficie agraria es de regadío, pero aporta el 55\% de la Producción Agraria Nacional (MAPA, 2003). El valor de la producción agrícola en la provincia de Alicante en el año 2000 ascendía 979,9 millones de euros, que equivalían al 34,1\% del total de la Comunidad Valenciana y al 2,7\% de España. En 2006, la agricultura alicantina representó, según datos del Instituto Nacional de Estadística, el 2,9\% del Producto Interior Bruto provincial; valores que se han mantenido bastante estables desde el año 2000. Este incremento, aunque inferior al de otros sectores, como por ejemplo, la construcción, es superior al registrado por las provincias de Valencia, Castellón o la propia media nacional, lo que reafirma la rentabilidad de ciertos aprovechamientos, especialmente los hortícolas y, en menor medida, los cítricos. El conjunto de estas producciones se localiza básicamente, en los municipios que se beneficiaron de las mejoras de dotaciones hídricas después de 1978 con la llegada de los primeros caudales del acueducto Tajo-Segura. 
La orientación hacia cultivos de elevada rentabilidad ${ }^{6}$, el carácter eminentemente exportador de frutas y hortalizas (el $80 \%$ de la producción se destina a satisfacer las demandas de los mercados de la UE y Europa Central — Rico y Morales, 2003-_-), la ampliación de mercados y la competitividad de los productos hortofrutícolas alicantinos se evidencia, entre otras realidades, en el incremento constante en el valor de su producción agrícola, que registró un aumento de un 15,3\% entre 1995 y 2000 (Hernández, Legua y Melián, 2004) y en torno al 10\% entre 2000 y 2005 (Generalitat Valenciana, 2007), es decir, corresponden a una oferta de productos capaces de ser cada vez más representativos dentro de las exportaciones de la provincia y teniendo un mejor comportamiento que el resto de sectores productivos ante los retos de los mercados globalizados (Albertos y Chinchilla, 2007: 295). Otro rasgo que caracteriza a esta agricultura es el hecho de que estas producciones intensivas apenas han recibido apoyos económicos de la sección Garantía de FEOGA para el mantenimiento de precios y mercados agrarios. A modo de ejemplo, se puede indicar que de los 6.257 millones de euros repartidos por el FEGA (ayudas directas del FEOGA-Garantía) en 2005, únicamente 11,5 fueron destinados a frutas y hortalizas, concretamente a retirada (FEGA, 2006). Dicho importe resulta poco significativo si se compara con los 5.488 millones de euros distribuidos por el Fondo Español de Garantía Agraria como pagos compensatorios a los cultivos industriales, cereales, aceite y a producciones lácteas y cárnicas. A diferencia de lo que ocurre con las explotaciones agrarias del interior de España, que en muchos casos dejarían de ser rentables si desapareciesen las primas comunitarias, esta agricultura se caracteriza por su fuerte dinamismo, tecnificación y participación de capital privado.

Este dinamismo productivo y comercial se vincula a diversos factores (naturales y de organización). Entre los factores naturales se debe mencionar la escasa frecuencia de heladas, la insolación y la luminosidad (con más de $80 \%$ días despejados) que permiten el cultivo intensivo en regadío en invierno, con rotaciones de 2 y 3 cosechas de octubre a mayo sobre una misma parcela, al tiempo que se pueden practicar cultivos cuasi tropicales (cítricos y aguacate). La mayor luminosidad permite también el cultivo bajo plástico en invernaderos sin calefacción, lo que se traduce en un importante ahorro energético. La proliferación de invernaderos dotados con tecnología de vanguardia permite obtener producciones continuadas de algunas hortalizas durante todo el año (pimiento, tomate, etc.) con un consumo mínimo energético adicional. De esta forma, su capacidad productiva y comercializadora se encuentra operativa desde otoño a primavera, precisamente cuando los mercados europeos ofrecen las mejores cotizaciones por estos productos, al registrarse una menor competencia con otras regiones productoras, que están dotadas con peores condiciones climáticas (interior peninsular, valle del Ebro y otras regiones productoras de Europa).

En los factores organizativos resulta significativo que la mayoría de las explotaciones hortofrutícolas y las cooperativas agrarias están adoptando los sistemas de cultivo más avanzados y de calidad ambiental, que demandan los mercados internacionales más exigentes de Europa. De forma creciente, muchos invernaderos se acogen al control biológico de plagas y a sistemas de biofumigación para eliminar el empleo de productos fitosanitarios. En las cooperativas agrarias, se ha recurrido, también, a integrar todas las fases de producción, clasificación, envasado y transporte a partir de las formas más modernas de trazabilidad, que permiten ofrecer al consumidor final un historial fitoclínico del producto adquirido. Estos esfuerzos se hayan en relación con la obtención por parte de muchas empresas y

6 De los 66 aprovechamientos que se practican en la provincia de Alicante en 2006, tan solo 14, que corresponden casi en su totalidad a cítricos y hortalizas, concentran el $88 \%$ del valor económico de la agricultura. Sin embargo, las mayores superficies se dedican a almendro, olivo y vid. 
cooperativas agrarias de los certificados AENOR y EurepGAP. La concentración de la oferta de hortalizas y frutas mediante la configuración de organizaciones de productores agrarios como las cooperativas o las sociedades agrarias de transformación resulta también decisivo para afianzar esta agricultura intensiva (Rico y Morales, 2003). La configuración de empresas asociativas agrarias (EAAs) tiene como finalidad la concentración de la oferta de las cosechas obtenidas en las explotaciones para una mejor comercialización, además de beneficiarse sus asociados de economías de escala que se generan para acceder a suministros y a servicios agrarios más baratos. La cooperativa Surinver (Pilar de la Horadada, Alicante), integrada dentro de la cooperativa de segundo grado ANECOOP, fue pionera en España en materia de asociacionismo, prestación de servicios a los agricultores, producción integrada, control de calidad, automatización de las fases de manipulación en almacén y comercialización internacional. Por último, estas producciones cuentan, frente a las producciones de países no comunitarios, con otro insumo favorable, el de su rápida llegada a los mercados y a su mejor infraestructura logística apoyada básicamente en una buena accesibilidad. Estas comarcas se encuentran unidas a los mercados finales por vías rápidas como la autopista A-7 (E-15) que permite colocar las producciones en los mercados receptores en menos de 36 horas desde el momento de su recolección. De esta forma, su presentación comercial se hace en mejores condiciones que las hortalizas procedentes de otros países de la cuenca mediterránea o de ultramar, dado el mayor tiempo utilizado en el transporte. Así, se puede compensar unos mayores costes de producción frente a países de la ribera sur del Mediterráneo y del hemisferio austral.

Las transformaciones descritas han dado como resultado la consolidación de unas clases trabajadoras y de una agricultura familiar de poder adquisitivo medio, medio-alto, muy dinamizadoras de todo el territorio afectado por estas actividades socioeconómicas. El incremento demográfico, todavía en progreso, tanto por el crecimiento vegetativo como por el saldo migratorio, se basó en los elevados ingresos económicos que obtenían las unidades familiares. A principio de la década de los ochenta, hasta cuatro o cinco miembros de la unidad familiar trabajaban como asalariados para pasar años después a constituir sus propias empresas agrícolas en las que colaboraban todos los miembros de la unidad familiar. La actividad agraria además de proporcionar ocupación durante todo el año, aportaba unos salarios superiores a los que se percibían en otras regiones agrícolas españolas, en las que predominaban aprovechamientos extensivos. Ese diferencial se ha mantenido a lo largo del tiempo. En 1996, Morales (1997: 40) indica que los salarios pagados a obreros no especializados se situaban alrededor de $36 €$ /día frente a un valor medio de unos 24 en otras regiones. Elevándose estos salarios hasta los $60 €$ /día para agricultores especializados y con jornadas laborales de 8 horas. Los salarios de los contratados fijos en horticultura oscilaban entre 750 y los $1.500 €$ mensuales. Éstos en 2008, han alcanzado valores medios de unos $6,25 €$ /hora para los peones, unos 50 €/día y unos 70 €/día para trabajadores cualificados. La mayor disponibilidad de renta familiar queda evidenciada, asimismo, por diversos indicios de tipo cualitativo, entre los que cabe citar la renovación de gran parte de la estructura edificatoria de los municipios, la proliferación de entidades bancarias, con índices de oficina por habitante de los más altos de España o de concesionarios de coche de gama media-media alta, entre otros indicadores de consumo (La Caixa, 2008).

\section{Epílogo: retos de futuro de los regadíos intensivos}

Esta agricultura de alto rendimiento es capaz de aportar producciones para satisfacer las demandas de los mercados internacionales, desde mediados de otoño a finales de la primavera, sin que las condiciones climáticas del periodo invernal incidan negativamente 
en su ritmo productivo. Nos encontramos, por tanto, ante una agricultura con una clara orientación a la exportación: el $80 \%$ de la producción se destina a satisfacer las demandas de los mercados de la UE (Rico y Morales, 2003). El beneficio de estos cultivos se relaciona con otro elemento fundamental como es la productividad del agua, concretamente, de un $\mathrm{m}^{3}$, que resulta muy elevada, dado el alto valor que alcanzan los productos en el mercado. La producción bruta de un cultivo de cereal en La Mancha se situaría entre 0,12 y 0,18 $€ / \mathrm{m}^{3}$ frente a los 0,55 de los cítricos y 0,80 de los hortícolas al aire libre; elevándose ésta a unos 3 euros en el caso de aprovechamientos en invernadero (Melgarejo, 2004). A esta rentabilidad, se le une su capacidad para generar empleo. Para ello, solo hay que fijarse en el hecho de que las 950 hectáreas dedicadas al cultivo de lechugas generan una demanda de mano de obra de uno 4.000 empleos directos, casi el $40 \%$ de los que necesitan los cítricos, con sus 27.000 hectáreas cultivadas. En términos de consumo de agua, toda la superficie dedicada al cultivo de la lechuga consume al año unos $5,7 \mathrm{hm}^{3}$ frente a los 162 $\mathrm{hm}^{3}$ de los cítricos.

Este territorio se ha mostrado, además, en los últimos treinta años, como el que presenta un elevado dinamismo desde el punto de vista de la difusión de las nuevas tecnologías de riego aplicadas a la agricultura innovadora. Los cultivos hortícolas y los cítricos suelen caracterizarse por la implantación de sistemas eficientes de riego localizado por goteo y microaspersión, que abarcaría más del $70 \%$ de esta superficie cultivada y se elevaría casi al $100 \%$ en los terrazgos irrigados creados ex-novo tras la llegada de los caudales del trasvase, ahora sustituidos, en parte, por los obtenidos mediante depuración y desalación. A pesar de su trascendencia social y económica, estos regadíos intensivos son objeto a veces de duras críticas por el consumo de agua que realizan. Éstas no siempre están fundadas, ya que en términos comparativos con otros cultivos, obtienen por $\mathrm{m}^{3}$ consumido, una elevada productividad $^{7}$ y una importante generación de empleo. A pesar de esta rentabilidad, cuando ha empezado a escasear el agua para uso agrario, se plantea la duda de si se está haciendo un buen manejo de ella. Para ello, habría que apostar por aquellos aprovechamientos competitivos en los mercados internacionales, hortícolas y algunos cítricos (mandarinas tempranas y naranjas tardías) y suprimir de la práctica agrícola aquéllos de escasa trascendencia socioeconómica. Ésta situación se agrava por el hecho de que utilizan para su mantenimiento caudales que son costosos de conseguir, cuando no casi imposibles. Tal vez con un buen ordenamiento del ager en regadío de estos municipios, con una reducción de superficies, como ya se apunta, y un consumo menor de agua, se pueda generar más empleo y producir mayor beneficio socio-económico. Resulta demostrativo y esclarecedor lo que está ocurriendo en Pilar de la Horadada, Benferri o Elche, éste último incrementando su vocación hacia el cultivo de las flores, que en 2005, suponía el 30\% de la producción nacional (MAPA, 2007: 60). Esta posible reordenación de cultivos choca con las estructuras de propiedad y tenencia de la tierra. Así, se evidencia que las posturas más conservadoras, que hacen una menor inversión pero que, a su vez, generan menores beneficios sociales y económicos, se corresponden con los cultivos de cítricos, excluyendo las variedades extratempranas y tardías. Se identifican, generalmente, con propietarios de superficies entre 10 y más de 100 hectáreas, que prefieren arriesgar menos, resultando sus actitudes cada vez más conservadoras e inmovilistas. De otro lado, se observan unos posicionamientos de mayor

7 Ésta se sitúa entre los 2.0000 y 6.000 €/ha/año para cultivos como los cítricos o el granado y se elevan notablemente en el caso de tomates, pimientos o flores, donde ésta puede situarse alrededor de los 30.000 €/ha/año (Melgarejo, Martínez y Martínez, 2004: 126; Morales, 2003; Rico y Hernández, 2008). Estas cifras contrastan notablemente con una hectárea de cereal (trigo blando) que ascendería a unos $520 €$, que se reducirían a 232 sin las ayudas de la PAC (Loring, Millan y Vicario, 2002; García y Gallego, 2006). 
riesgo, entendido en términos de inversión, en los cultivos hortícolas, entre los propietarios de explotaciones de unas 10 hectáreas. Son, así, los más emprendedores y dinamizadores de los regadíos de la horticultura de ciclo manipulado.

A pesar de la rentabilidad social y económica puesta de manifiesto en epígrafes anteriores, esta agricultura muestra ciertos indicios de vulnerabilidad, que, grosso modo, pueden sintetizarse en los siguientes hechos:

1.- La disponibilidad de agua es vital. Si bien no es el insumo que genera el mayor capítulo de gasto, aunque en ocasiones llegue a pagarse a $0,50 € \mathrm{~m}^{3}$. Es conveniente que estos caudales, aunque cada vez sean menores en volumen, no procedan en su totalidad de la desalación, sino que es necesario disponer de otros recursos, superficiales, incluido los del Tajo-Segura, subterráneos y de depuración, pues en momentos de crisis energética y el riesgo que representa el transporte de membranas de desalación, desde Japón o Estados Unidos, se puede crear una situación de incertidumbre en la producción de agua desalada. En definitiva, estos agricultores exigen complementariedad de fuentes de suministro de agua y seguridad en su disponibilidad. Además, desde el 30 de junio de 2008 ha desaparecido la tarifa eléctrica nocturna de la que se beneficiaban los agricultores para elevar y, sobre todo, para mover los sistemas de riego localizado que han sustituido en estas comarcas a los de gravedad, a manta, impulsados estos cambios desde las administraciones autonómicas y central, lo que va a representar un aumento de la factura eléctrica de estas explotaciones entre un 20 y un $40 \%$, según estimaciones de algunas asociaciones agrarias. A consecuencia de este incremento del gasto energético el coste final de las producciones hortofrutícolas se verá incrementado; por ello, se está ya afirmando que si no se compensa con una subida de precios de los frutos en los mercados de origen, se puede llegar a abandonar entre el 10 y el $15 \%$ de las explotaciones actuales, sobre todo, de cultivos leñosos.

2.- Una mayor independencia de los insumos que proceden de otros países para su puesta en producción: plántulas, semillas, fertilizantes, funguicidas, plásticos, etc. Ésta, entendida en términos de $\mathrm{I}+\mathrm{D}$, se traduce, por un lado, en una marcada sumisión a productos externos, además de ser un input gravoso, dados los elevados costes que tienen semillas, insectos para la lucha biológica, etc. Las posibilidades de supervivencia de parte de agricultura y de competir con mercados con menores costes salariales se vincula a la incorporación de este segmento productivo. Ello permitiría compensar el aumento de gastos de producción asociados al aumento del petróleo y sus derivados.

Tabla 5.

VALOR MONETARIO DE LOS SALARIOS EN 2007 EN ALGUNOS PAÍSES CUYA PRODUCCIÓN HORTOFRUTÍCOLA COMPITE CON LA ESPAÑOLA

\begin{tabular}{|l|c|c|c|}
\hline & $\begin{array}{c}\text { Salario } \\
(€(\text { día })\end{array}$ & $\begin{array}{c}\text { Jornada laboral } \\
(\mathrm{h} / \text { día })\end{array}$ & Seguridad Social \\
\hline Holanda & 70 & 8 & $\mathrm{Si}$ \\
España & $\mathbf{4 5 - 5 0}$ & $\mathbf{8}$ & $\mathbf{S i}$ \\
Turquía & 21 & 8 & Dudosa \\
Marruecos & 9 & Poco definida & No \\
\hline
\end{tabular}

Fuente: Morales, 2006. 
3.- Los costes de la mano de obra pueden provocar una caída en la rentabilidad en algunos de los cultivos practicados hasta ahora, como está acaeciendo ya en algunas variedades de cítricos, y una pérdida de rentabilidad frente a importaciones procedentes de la ribera sur del Mediterráneo con costes de mano de obra mucho más bajos que en estas comarcas (Tabla 5). Es necesario, apostar, por cultivos o por sistemas de producción que incrementen los beneficios a los agricultores (manipulación, constitución de empresas asociativas agrarias, etc.) como en su momento realizó Holanda para defenderse de la oferta de cultivos hortícolas procedentes de Almería y de la costa murciano-alicantina.

4.- La organización empresarial agrícola, grandes empresas y cooperativas, debe apostar por la mejora y consolidación de unas buenas redes logísticas, que permitan incrementar el valor final del producto. Vinculado a este factor, es necesario dotar al arco mediterráneo español de una buena red de ferrocarriles de mercancías que vayan sustituyendo y/o complementado a los camiones para el transporte de mercancías; evitando de este modo, posibles, pérdidas económicas y de mercados por desabastecimiento en situaciones de bloqueo de carreteras o huelgas en el sector del transporte terrestre.

5.- La atención, por parte de las administraciones autonómica y estatal, a estas formas productivas, de gran interés por su repercusión en el PIB, asegurando el agua necesaria y no como hasta ahora, que es contemplada, en cierto modo, dubitativa. No debe de olvidarse que el sector de frutas y hortalizas concentró el 20,6\% de las exportaciones valencianas en 2006.

\section{Bibliografía}

ALBERTOS, Mª.V. y CHINCHILLA, A. (2007): Anuario de la agricultura y la ganadería 2006. Alicante, Jóvenes Agricultores y Diputación Provincial de Alicante.

BELLO, A.; LÓPEZ-PÉREZ, J.A. y GARCÍA ÁLVAREZ, A. (2003) Biofumigación en agricultura extensiva de regadio, Alicante, Ed. Mundi-Prensa y Fundación Caja Rural, 670 pp.

CAIXA, LA (2008). Anuario económico 2007.Barcelona, La Caixa. Servicios de Estudios. Disponible en http://www.anuarieco.lacaixa.comunicacions.com

CANALES MARTÍNEZ, G. (dir.) (1995): El Bajo Segura: estructura espacial, demográfica y económica. Alicante, Universidad de Alicante.

CONSELLERIA DE AGRICULTURA, PESCA Y ALIMENTACIÓN: Superficies ocupadas por cultivos agrícolas. Hojas 1-T. Varios años: 1979, 1998 y 2006.

CONSELLERIA DE AGRICULTURA, PESCA Y ALIMENTACIÓN (2007): Informe del sector agrario valenciano, 2006. Valencia, Generalitat Valenciana. Disponible en http://www.gva.es/ jsp/portalgv.jsp? deliberate $=$ true.

CONSELLERIA DE AGRICULTURA, PESCA Y ALIMENTACIÓN (2008): Datos básicos del sector agrario valenciano. Septiembre, 2007. Valencia, Generalitat Valenciana. Disponible en http://www.gva.es/jsp/portalgv.jsp?deliberate=true).

COLINO SUEIRA, J. y MARTÍNEZ PAZ, J.M. (2002): «El agua en la agricultura del sureste español: productividad, precio y demanda» en La agricultura mediterránea en el siglo XXI (García Álvarez Coque, J.M., coord.). Almería, pp. 199-222.

FEGA (2006): Informe de actividad. Año 2005. Madrid. MAPA.

GARCÍA LORCA, A. (2006): «Cambios tecnológicos y flujos migratorios. el caso de la agricultura intensiva en Almería (España)». en II Simposio Internacional sobre Desertificación y migraciones Almería. Disponible en http://www.sidym2006.org/esp/esp_ponencias_conclusiones.asp).

GIL OLCINA, A. (1988): «Evolución de los grandes regadíos deficitarios del Sureste Peninsular» en Demanda y Economía del Agua en España (Gil Olcina, A. y Morales Gil,A., eds.). Alicante, Universidad de Alicante, pp. 331-327. 
GOZÁLVEZ PÉREZ, V. (1973): «El Bajo Vinalopó», en Geografía de la provincia de Alicante. Alicante, Diputación Provincial de Alicante, pp. 557-578.

HERNÁNDEZ GARCÍA, F.; LEGUA MURCIA, P. y MELIÁN NAVARRO, A. (2004): «Influencia del Plan Hidrológico Nacional en el empleo agrícola de la provincia de Alicante» en Repercusiones socioeconómicas del Plan Hidrológico Nacional en la provincia de Alicante (Melgarejo Moreno, J., ed.). Alicante, COEPA, pp. 147-162.

HERNÁNDEZ HERNÁNDEZ, M. y TORRES ALFOSEA, F.J. (2003): «Población y ciudades del Bajo Segura» en Cultura, paisajes y sociedades en el eje de desarrollo territorial del Bajo Segura y Campo de Cartagena (Morales Gil, A., ed.). Murcia, Ministerio de Fomento, pp. 157-194.

JÚAREZ SÁNCHEZ-RUBIO, C. (1991): Planificación hidrológica y desarrollo económico: el Trasvase Tajo-Segura. Alicante, Instituto de Cultura Juan Gil Albert.

JÚAREZ SÁNCHEZ-RUBIO, C. (1996): «Aumento de recursos de agua: nuevas tecnologías y repercusión socioeconómica en la Vega Baja y Baix Vinalopó». Investigaciones Geográficas, nº 15, pp. 61-78.

JÚAREZ SÁNCHEZ RUBIO, C. (2004): «Asignación de recursos de agua para uso agrario y crecimiento económico en la comarca meridional agraria de Alicante». Revista de Estudios Agrosociales y Pesqueros, $n^{\circ}$ 202, pp. 135-166.

INSTITUTO NACIONAL DE ESTADÍSTICA (INE): Censos de población: 1970, 1971, 1991 y 2001. Madrid. Disponible en http://www.ine.es/inebmenu/mnu_cifraspob.htm.

INSTITUTO NACIONAL DE ESTADÍSTICA (INE): Padrón municipal a 1 de enero de 2007. Madrid. Disponible en http://www.ine.es/inebmenu/mnu_cifraspob.htm.

INSTITUTO VALENCIANO DE ESTADÍSTICA (IVE): Encuesta de población activa, 2001. Valencia, Generalitat Valenciana. Disponible en http://www.ive.es/portal/page/portal/IVE_PEGV/ CONTENTS/epa/ini_cas.htm).

LÓPEZ ORTIZ, M.I. y MELGAREJO MORENO, J. (2007): «El fin del regadío tradicional y la creación de sociedades mercantiles para la venta de agua. Riegos de Levante, margen derecha del Segura». Boletín de la AGE, $n^{\circ}$ 43, pp. 307-334.

MAPA (2003): Plan Nacional de Regadios. Madrid, MAPA. Disponible en http://www.mapa.es/es/ desarrollo/pags/pnr/principal.htm.

MAPA (2007): Hechos y cifras de la agricultura, la pesca y la alimentación en España. Madrid, Ministerio de Agricultura, Pesca y Alimentación. Disponible en http://www.mapa.es/es/ministerio/pags/hechoscifras/introhechos.htm9.

MELGAREJO MORENO, J. (2000): «Balance económico del trasvase Tajo-Segura». Investigaciones Geográficas, pp. 69-95.

MELGAREJO MORENO, P.; MARTÍNEZ NICOLÁS, J.J. y MARTÍNEZ TOMÉ, J. (2004): «Productividad y rentabilidad de agua de riego en la provincia de Alicante» en Repercusiones socioeconómicas del Plan Hidrológico Nacional en la provincia de Alicante (Melgarejo Moreno, J., ed.). Alicante, COEPA, pp. 103-143.

MORALES GIL, A. (1996): «Escasez y rentabilidad del agua en el Sureste de España: agricultura de vanguardia, huertas tradicionales, nuevos regadíos y medio ambiente en el valle del Segura» en Medio ambiente y crisis rural (García Fernández, J., ed.). Valladolid, Fundación Duques de Soria, pp. 131-157.

MORALES GIL, A. (1997): Aspectos geográficos de la horticultura de ciclo manipulado. Alicante, Universidad de Alicante.

MORALES GIL, A. (2003): «Eficiencia de los regadíos españoles». Cuadernos de Geografía, nº 73-74, pp. 323-342.

MORALES GIL, A. (2006): «Los recursos de agua como elemento estratégico en el desarrollo territorial de Murcia.» En Seminari Recursos Hídrics en l'eurorregio Pirineus-Mediterrània. Valencia.

MORALES GIL, A.; RICO AMORÓS, A.M. y HERNÁNDEZ HERNÁNDEZ, M. (2005): «El trasvase Tajo-Segura». Observatorio Medioambiental, $\mathrm{n}^{\circ}$ 8, pp. 73-110.

PÉREZ MORALES, A. (2008): «Rentabilidad socioeconómica de los cultivos con riego localizado en la región de Murcia». en Los espacios rurales españoles en el nuevo siglo. Actas del XIV Coloquio de Geografía Rural (Gómez Espín, J.Ma . y Martínez Medina, R., eds.). Murcia, Universidad de Murcia. Servicio de Publicaciones, pp. 181-198. 
OLCINA CANTOS, J. (2003): «El medio físico: un territorio intensamente transformado» en Cultura, paisajes y sociedades en el eje de desarrollo territorial del Bajo Segura y Campo de Cartagena (Morales Gil, A., ed.). Murcia, Ministerio de Fomento, pp. 51-84.

RICO AMORÓS, A.M. y HERNÁNDEZ HERNÁNDEZ, M. (2008): «Ordenación del territorio, escasez de recursos hídricos, competencia de usos e intensificación de las demandas urbano-turísticas en la Comunidad Valenciana». Documents d'Analisi Geografica, 51, pp. 79-109.

RICO AMORÓS, A.M. y HERNÁNDEZ HERNÁNDEZ (2008): «El sector agrario y su adaptación a la PAC en los últimos veinte años». en Las agriculturas españolas y la política comunitaria: 20 años después (Araque Jiménez, E.; Gallego Simón, V.J.; Sánchez Martínez, J.D. y Valle Buenestado, B., eds). Jaén, Universidad Internacional de Andalucía, pp. 15-43.

RICO AMORÓS, A.M. y MORALES GIL, A. (2003): «Regadíos hortícolas y frutícolas» en Cultura, paisajes y sociedades en el eje de desarrollo territorial del Bajo Segura y Campo de Cartagena (Morales Gil, A., ed.). Murcia, Ministerio de Fomento, pp. 221-246.

RUIZ CANALES, A. y MELIAN NAVARRO, A. (2006): «Actividad agraria en las comarcas del sur de Alicante y competencia con otros sectores por los usos del agua y del suelo». Papeles de Geografía, no 43, pp. 105-119.

VERA REBOLLO, J.F. (1984): Tradición y Cambio en el Campo del Bajo Segura. Alicante, Instituto de Estudios Alicantinos. 